DOI: $10.20472 / E S .2015 .4 .4 .004$

\title{
THE MARRIAGE PREMIUM AND PRODUCTIVITY: THE CASE OF NBA PLAYERS
}

\section{ZE'EV SHTUDINER}

\begin{abstract}
:
Numerous studies have shown that there is a marriage premium among male workers - married men's wages are higher than those of single men. One explanation for the existence of a marriage premium is increased productivity. While the estimation of workers' productivity in the standard labor market is often inaccurate and subjective, throughput can be estimated easily in professional sports. This study examines whether a marriage premium exists in relation to the performance and efficiency of professional league basketball players in the United States (NBA). A total marriage premium of $16.4 \%$ was found in a comprehensive analysis of the performance of all league players. $\mathrm{A}$ more thorough analysis showed that there is a higher marriage premium among international players compared to American players.
\end{abstract}

\section{Keywords:}

Productivity, wage gap, marriage, basketball

JEL Classification: J31, J70

\section{Authors:}

ZE'EV SHTUDINER, Ariel University, Israel, Email: zeevs@ariel.ac.il

\section{Citation:}

ZE'EV SHTUDINER (2015). The Marriage Premium and Productivity: The Case of NBA Players. International Journal of Economic Sciences, Vol. IV(4), pp. 53-65., 10.20472/ES.2015.4.4.004 


\section{Introduction}

Efficiency, productivity, specialization and wages are concepts that are not usually mentioned within the context of marriage and marital status. However, a number of studies dealing with the question of why some employees receive higher wages than others raised the marital status of the individual as one of the possible answers to this question. The main conclusion in standard cross-sectional log wage regressions is that married men are estimated to earn roughly 10-40 percent higher wages than their single counterparts. There are a number of proposed explanations for why married men earn more than single men. One of the explanations is that marriage has a positive effect on workers' productivity. Professional sports allow us to directly and objectively measure productivity. We used a unique database that we complied on professional basketball players to analyze the effect of the marriage premium among American players and international players.

Kenny et al. (1979) found that the average wages of married men is $8 \%$ to $30 \%$ higher than the average wage of single men. These significant differences suggest that marital status has great importance, along with other factors such as race and gender, when it comes to influencing wages. The marriage premium exists for all ages, especially individuals aged 45 and older. Marital status affects one's wages, even when other variables are controlled for, such as age, education and professional experience. Using data from the German Socio-Economic Panel, Pollmann-Schult (2011) found that married men enjoy a wage premium even after controlling selfselection into marriage. The researcher also found that men married to non-working partners receive a larger wage premium than do men married to a full-time working partner.

Schoeni (1990) found that there is a high and significant marriage premium among men in all of the 12 western countries examined. Hill (1979) found that married men have higher wages than widowed, divorced and separated men, who all earn higher wages than single men. The researcher controlled for other variables such as human capital, employment history, health status, occupation and number of children. Greenhalgh (1980) examined the labor market in Britain between 1971 and 1975 and found a significant marriage premium. Another study found that married men, aged 55-64 earn 20\% to 32\% more than unmarried men (Bartlett and Callahan 1984).

A prominent study in this field was the research conducted by Korenman and Neumark (1991). The researchers used two samples: a comprehensive survey data in the United States in 1984, and the personal data of the white employees in a large U.S. manufacturing company from 1976. Employee data included performance ratings by their superiors and a "worker's grade" - an estimate of worker productivity, relevant to the promotion of the employee within the company. It was found that marriage had a significant impact on wages, even when other variables were controlled for. The more years the employee was married, the higher the marriage premium was found to be. These findings suggest that the marriage premium also exists among a 
homogeneous group of workers in the same field. The company tended to promote married men to a greater extent, rather than pay them higher wages than unmarried men in the same position with the same level of "worker grade". Married workers also received higher performance ratings from their superiors. These ratings increased their chances for promotion and the chance to receive higher wages.

Finding an explanation for the marriage premium is interesting because it can lead to a better understanding of how the wages of individuals are determined. In the labor market, the marriage premium is also important within the context of delayed marriage, increased divorce rate and the sharp increase in working married women (especially mothers with young children). The existing literature offers several reasons that can explain the marriage premium in regard to wages. First, employers see an employee's marital status as a symbol of stability and responsibility; therefore, there is more of a tendency to reward married employees (Hundley, 2000; Hill, 1979). This explanation is difficult to verify, but it is possible to analyze whether the marriage premium has changed over the years in the U.S. (along with the changing perception about the importance of marriage itself in American society). The marriage premium decreased by 10\% from 1967 to 1988 (Blackburn and Korenman 1994); therefore, it is possible that the change in social values led to the decreased premium.

Second, other economists argue that the relationship is, in fact, in the opposite direction. Married men earn more because the characteristics that make employees earn higher wages are the same characteristics that help married men become good spouses. Job-related stability and responsibility can be a reflection of the stability and responsibility in one's personal life (Becker, 1981; Keeley, 1977). Researchers have shown evidence supporting this hypothesis (Nakosteen and Zimmer, 2001). They found that men with the potential to earn higher wages get married and stay married at a higher rate than those with less earning potential.

Third, being married is helpful because it allows men to work longer hours (Knowles, 2013; Becker, 1985). Becker showed that Wage differences between men and women result in women devoting more time to the household and men devoting more time to work. Becker showed that the benefits of marriage are higher for men with higher wages than for men with lower wages because they have a higher incentive to work more hours. Parsons (1977) found that married men work 260 hours a year more than single men. In contrast, another study showed that there is no difference between married men and single men regarding the time they devote to their household (Hersche and Leslie 2000).

Fourth, since divorced and separated men earn higher wages than men who have never married, arguably marriage has advantages, even after the marriage has ended (Kenny, 1983). Marital status can also affect incentives to accumulate human capital. Men who expect to be married for most of their lives will earn significantly increasingly higher wages, since their incentive to accumulate human capital is higher than that of 
unmarried men. Kenny (1983) presented a theoretical model that supports this hypothesis.

According to the last two explanations, the marriage premium is due to the effect of marriage on employee productivity. Professional sports allow for a direct, objective measurement of employee productivity, while in the labor market a differential output of workers is estimated according to subjective performance metrics provided by the workers' superiors. Cornaglia and Feldman (2011) investigated the effect of marriage on male productivity using a large sample of professional baseball players from 18712007. Despite the lack of any effect on productivity, high-ability married players earned roughly 16-20 percent more than their single counterparts.

This work examines whether there is a marriage premium regarding performance among NBA players ${ }^{1}$. NBA players are an interesting population, which allows for an analysis of the marriage premium as regards performance, which can be directly estimated by a range of measures. It is not possible to analyze the marriage premium in regard to wage, since in team sports, unlike personal sports, a player's wage does not necessarily entirely reflect his ability. In the NBA, for instance, there is a salary cap, which significantly affects players' salaries. The analysis includes additional explanatory control variables, such as age, years of experience, one's role in the group, nationality, number of children, etc.

We also analyzed whether there is a difference in the marriage premium between two specific populations: American players and international players. The number of international players has increased steadily - from 35 in the 1999-2000 season to 101 in the 2014-2015 season. However, Yang and Lin (2012) found that international players seem to receive a lower salary than that of their American counterparts playing in the NBA, suggesting the existence of salary discrimination according to nationality. Although not in the field of sports, Constant and Massey (2005) also studied the occupational progress and earnings attainment of immigrants in Germany over time, and compared them to native Germans. Both immigrants and natives experienced a marriage premium, but the boost was greater for immigrants rather than Germans. Our hypothesis is that a higher marriage premium exists among international players, compared to local players. We believe that marriage provides stability and support, which are more important to international players, who play away from home. Moreover, international players' wives may not be in a position to earn much in the U.S. because of relatively poor English and cultural differences.

1 The National Basketball Association (NBA) is the pre-eminent men's professional basketball league in North America, and is widely considered to be the foremost male professional basketball league in the world. 
The next section describes the data and presents descriptive statistics. Section 3 presents the model and Section 4 presents the results. Finally, in Section 5 we offer concluding remarks.

\section{Data}

The official NBA website (www.nba.com) includes data about all of the teams, the leading players in each category from 2004 onwards, and data on each player from his first season in the NBA league. Each player has a personal page where the fans can view statistics from last season, statistics throughout his career in the NBA, height, weight, etc. Each player also has personal information on his page, which differs from one player to another. This information can include marital status, number of children and their names, information about the player's parents and charitable activities. Data on the player's family (marital status and children) was validated through extensive work and by taking information from fans' blogs, gossip websites or from the websites and blogs of the players themselves.

The most commonly used statistical benchmark for comparing the overall value of players is called efficiency (EFF). It is derived by a simple formula:

EFF $=($ Points + Rebounds + Assists + Steals + Blocks $)-(($ Field Goals Attempts -

Field Goals Made) + (Free Throws Attempts - Free Throws Made) + Turnovers).

EFF is calculated for each player after each game. Seasonal EFF is the average efficiency including all games in which the player played. This index is common among NBA coaches and trainers in Europe as a quick and simple proxy for players' performance. Since this index does not take into account the number of minutes that the player has played, there is an index that normalizes EFF to 48 minutes (the length of a basketball game in the U.S.). This index is calculated as follows:

EFF48 $=\left(\mathrm{EFF}^{*} 48\right) /($ Minutes Per Game $)$

EFF48 doubles the player's efficiency per minute by 48 minutes, thus creating a basis for comparison between the different players playing a different number of minutes. This index is used less frequently, since it estimates performance less accurately. For instance, the EFF48 of a player who played for one minute and gained one point is equal to the EFF48 of a player who played for 24 minutes and gained 24 points. Clearly, the performance of the second player is much more significant and contributes more to his team. Therefore, we have used EFF as a proxy for performance.

The data includes the average seasonal EFF of all 451 players who played in all 30 league teams from the regular season, including 82 games (not including preparation 
games and playoff games that include only some of the groups). Out of 451 NBA players who played in the regular season, 172 players were married (38\%) and 128 players had at least one child (28\%). Table 1 presents descriptive statistics divided according to married and single players. The average age and years of experience of the players who are married is higher, as expected. In the League, there are 67 international players, representing $14.8 \%$ of the players. A higher percentage of international players are married compared to American players.

\begin{tabular}{|c|c|c|c|}
\hline \multicolumn{4}{|c|}{$\begin{array}{c}\text { Table } 1 \\
\text { Descriptive statistic }- \text { Married and unmarried players }\end{array}$} \\
\hline & $\begin{array}{c}\text { Married players } \\
\text { (average or } \\
\text { percent) }\end{array}$ & $\begin{array}{c}\text { Single players } \\
\text { (average or } \\
\text { percent) }\end{array}$ & $\begin{array}{c}\text { Overall } \\
\text { (average or } \\
\text { percent) }\end{array}$ \\
\hline Age & $\begin{array}{c}30.9 \\
(3.60)\end{array}$ & $\begin{array}{c}25.7 \\
(3.24)\end{array}$ & $\begin{array}{l}27.69 \\
(4.20)\end{array}$ \\
\hline Years of Experience & $\begin{array}{c}8.38 \\
(3.49)\end{array}$ & $\begin{array}{c}3.75 \\
(2.80)\end{array}$ & $\begin{array}{c}5.51 \\
(3.83)\end{array}$ \\
\hline $\begin{array}{l}\text { American players } \\
(\%)\end{array}$ & 37.2 & 62.8 & 100 \\
\hline $\begin{array}{l}\text { International players } \\
(\%)\end{array}$ & 43.2 & 56.8 & 100 \\
\hline Number of children & $\begin{array}{c}1.43 \\
(1.32)\end{array}$ & $\begin{array}{c}0.06 \\
(0.38)\end{array}$ & $\begin{array}{c}0.58 \\
(1.09)\end{array}$ \\
\hline
\end{tabular}

\section{$3 \quad$ Model}

We ran a regression to calculate the marriage premium, since there are other variables that can affect the player's performance. The regression equation is as follows:

$$
\begin{gathered}
\log (E F F)=\beta_{0}+\beta_{1} \text { age }+\beta_{2} \text { yearspro }+\beta_{3} \text { yearspro }^{2}+\beta_{4} \text { height }+\beta_{5} \text { guard }+ \\
+\beta_{6} \text { forward }+\beta_{7} \text { International }+\beta_{8} \text { married }+\beta_{9} \text { children }
\end{gathered}
$$

As mentioned in Section 2, the EFF Index is the best estimator of players' performance compared to other indexes. A logarithmic model, rather than a regular model, was used for three reasons. First, the distribution of the log is narrower and closer to a normal distribution than the standard distribution (see a comparison of the two distributions in Appendix I). Second, efficiency can have only positive values. Third, the results will display the effect in percentages, which makes more sense with respect to the dependent and independent variables. 
Married is a dummy variable that receives a value of 1 if the player is married and 0 if the player is single. It is hypothesized that this variable will be positive and significant. Children is the player's number of children. We speculate that this variable will also be positive $^{2}$. Besides these two important explanatory variables, other variables were included. The first two explanatory variables are player's age and years of experience in the NBA league. The expected effect of these variables on performance can be reversed after a certain age or years of experience. Therefore, we included two additional variables: age squared and years of experience squared. Such a regression demonstrated that years of experience affects performance in this way (a positive effect up to a certain value and then a negative effect), but not the age variable, which negatively affects any age. Therefore, in the final regression, we included only the squared variable for years of experience. Other independent variables are height and dummy variables for player's group position (guard and forward, if both of the variables receive 0 , the position is center), and dummy variable regarding the country of origin, International receives 1 if the player is not American and 0 if he is American.

To analyze whether there is a significant difference in the marriage premium between the different populations of players, we ran an additional regression with interaction variables, as displayed in the following equation:

$$
\begin{aligned}
\log (E F F) & =\beta_{0}+\beta_{1} \text { age }+\beta_{2} \text { yearspro }+\beta_{3} \text { yearspro }{ }^{2}+\beta_{4} \text { height }+\beta_{5} \text { guard }+ \\
+ & \beta_{6} \text { forward }+\beta_{7} \text { International }+\beta_{8} \text { married }+\beta_{9} \text { children }+ \\
+ & \beta_{10} \text { married } * \text { International }
\end{aligned}
$$

\section{$4 \quad$ Results}

First, we examined whether there is a difference between the performance of married players and unmarried players. Does marriage increase productivity? Figure 1 displays four seasonal measures of players' performance in regular season: Points, The sum of points, Rebounds and Assists $(P+R+A)$, EFF and EFF48 (the normalized effectiveness index for the whole game). The performance of married players is approximately $23 \%$ higher in comparison to unmarried players in the first three measures (the difference in EFF48 is only 4\%).

The results of the regression (Equation 1 in Section 3 ) can be seen in the second column from the left in Table 2 . Since the model is logarithmic, $100^{*}$ coefficient is approximately the percentage change in EFF given one unit of change in the independent variable. The higher the coefficient, the less accurate the approximation; therefore, in these cases we will present the exact percentage change of the dependent variable, which is $100{ }^{*} \exp \left(b_{i}{ }^{*} d x\right)-1$.

2 Years of marriage can also be an independent variable, but there is not enough available data. 


\section{Figure 1}

Performance of Married and Unmarried Players

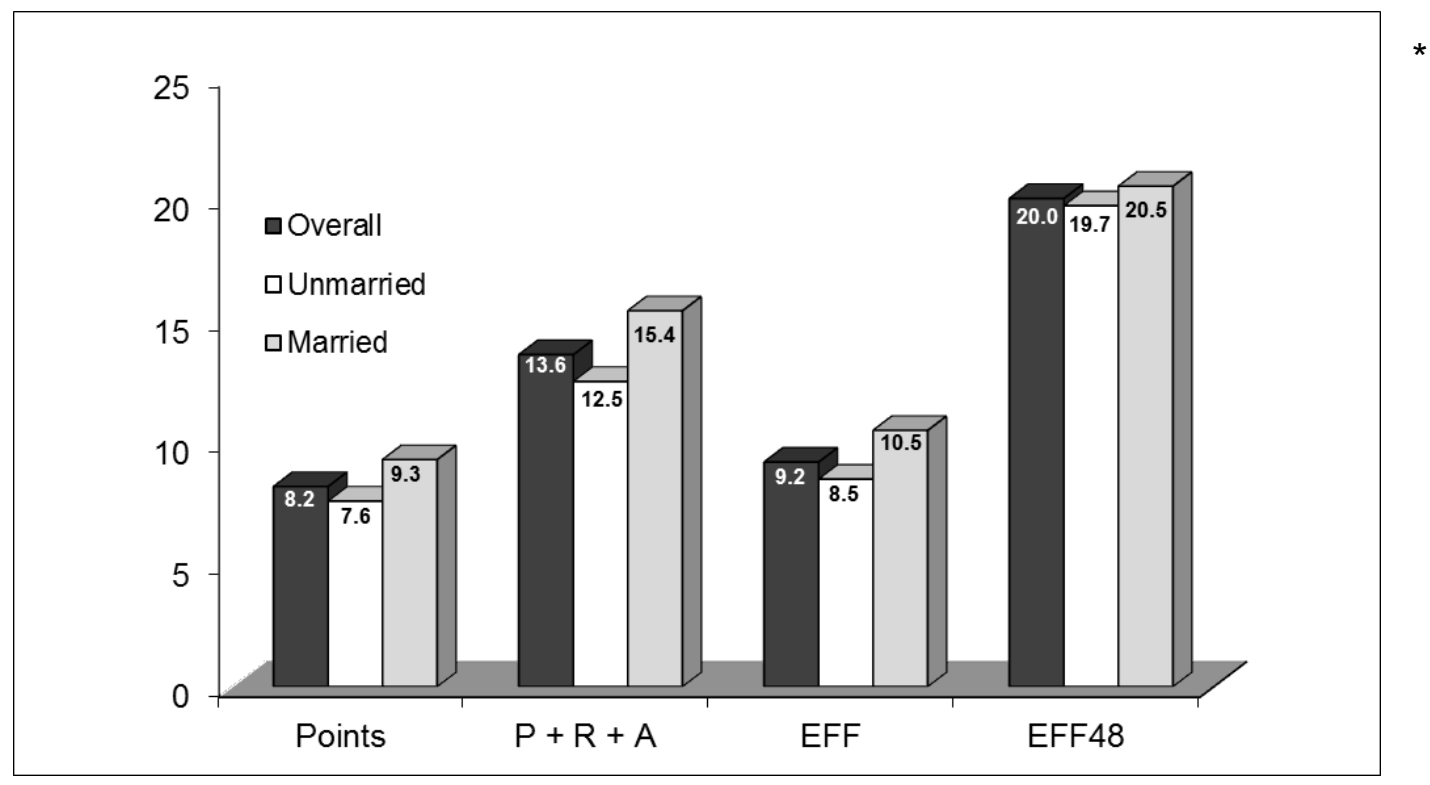

Regular season games

* The Figure includes four seasonal measures of players' performance: Points, The sum of points, Rebounds and Assists $(P+R+A)$, EFF and EFF48.

The marriage premium in regard to efficiency is significant and equal to $17.8 \%$ (or $16.4 \%$ based on the approximation, which is the coefficient of married). The effect of number of children is not significant. Player's age has, as expected, a negative impact on the player's efficiency. Given that all other independent variables are constant, each year reduces player's efficiency by $13.3 \%$ (exact coefficient). The positive coefficient of years of experience and the negative coefficient of the squared years of experience indicate that the early years of experience positively affect efficiency, but at a certain stage they have a negative effect. The turning point is 13 years of experience (the calculation is as follows: $\operatorname{Abs}\left(\beta_{\text {(yearspro) } / 2} \beta\right.$ (yearsproz))).

The coefficients of the height and position variables are low and not statistically significant. This result was expected, since for each position and height there are advantages and disadvantages regarding gaining efficiency. Tall players in forward and center positions, for example, gain more rebounds and blocks, compared to lower players in guard positions that gain more assists and steals. International players are more efficient by $52 \%$ compared to American players (exact coefficient). The path to the NBA is more difficult for international players compared to American players; therefore, only the finest players reach the league. According to the F-test, the entire model is significant and the adjusted $\mathrm{R}^{2}$ equals 0.216 . 


\section{Table 3}

Mean EFF - Distribution of different populations and marital status

\begin{tabular}{|c|c|c|c|c|c|c|}
\hline & \multicolumn{2}{|c|}{ Married Players } & \multicolumn{2}{c|}{ Single Players } & \multicolumn{2}{c|}{ Overall } \\
\hline & $\begin{array}{c}\text { Mean } \\
\text { EFF }\end{array}$ & Obs. & $\begin{array}{c}\text { Mean } \\
\text { EFF }\end{array}$ & Obs. & $\begin{array}{c}\text { Mean } \\
\text { EFF }\end{array}$ & Obs. \\
\hline American & 10.05 & 143 & 8.34 & 241 & 8.98 & 384 \\
\hline International & 12.71 & 29 & 9 & 37 & 10.76 & 67 \\
\hline
\end{tabular}

The third column from the left in Table 3 presents the results of Regression 2 (Equation 2 in Section 3). The population that appears in the regression is international married players, which form the base group. The coefficient of the variable married ${ }^{*}$ American is positive (the exact coefficicnt is $8.3 \%$ ), but it is not significant. In other words, married American players are not more effective than single Americans players.

The significance of the marriage premium among international players was tested using an F-test to examine whether the coefficient of the variable married*international is equal to the coefficient of the variable single*international. The null hypothesis was rejected, meaning that there is a marriage premium among international players. Marriage increases the efficiency of international players by $86 \%$ (the difference between the exact coefficients).

\section{$5 \quad$ Conclusions}

In this work, we focused on one of the explanations for the marriage wage premium for men - the effect of marriage on productivity. The analysis was performed using data on NBA players, workers whose productivity can be estimated directly by the efficiency index. In a general analysis of all players, a marriage premium in regard to productivity was found; married players are more efficient than single players. A more thorough analysis, distinguishing different populations, shows that there is a marriage premium among international players, but not among American players. This result sheds a different light on the relation between marriage and productivity. Marriage provides a framework, stability and a sense of responsibility, which is more important for international players joining a very competitive league in a foreign country with numerous challenges and travel demands. Therefore, marriage increases international players' performance more significantly. Following these findings, it is reasonable to assume that the marriage wage premium will be higher among these populations. This explanation is different from the current, traditional explanations that marriage enables higher productivity through more working hours or specialization and education. 
We should keep in mind that the model in this paper is a simplification of reality and other important factors can be considered. For example, how do player performances change over time when they move from single to married and perhaps to single again? Another important factor is the number of children. This variable may have a positive effect on workers' productivity, but is not necessarily correlated with marriage (some players are not married but have children - divorced, have serious relationships, etc). Future research can incorporate those factors using panel data, with an analysis of players' efficiency over the years.

\section{References}

Bartlett, R. \& Callahan, C. (1984). Wage determination and marital status: Another look. Industrial Relations, 23(1), 90-96.

Becker, G. (1981). A Treatise on the family. Cambridge: Harvard University Press.

Becker, G. (1985). Human capital, effort, and the sexual division of labor. The Journal of Labor Economics, 3(1), S33-S58.

Blackburn, M. \& Korenman, S. (1994). The declining marital- status earnings differential. Journal of Population Economics, 7(3), 249-270.

Constant, A. \& Massey, D. (2005). Labor market segmentation and the earnings of German guestworkers. Population Research and Policy Review, 25(5), 489-512.

Cornaglia, F. \& Feldman, N.E. (2011). Productivity, wages, and marriage: The case of major league baseball. IZA Discussion Paper No. 5695.

Greenhalgh, C. (1980). Male-female wage differentials in Great-Britain: Is marriage an equal opportunity?, Economic Journal, 90, 751-775.

Hersche, J. \& Stratton, L. (2000). Household specialization and the male marital wage premium. Industrial and Labor Relations Review, 54(1), 78-94.

Hundley, G. (2000). Male/female earnings differences in self-employment: The effects of marriage, children, and the household division of labor. Industrial \& Labor Relations Review, 54(1), 95-114.

Hill, M. (1979). The wage effects of marital status and children. Journal of Human Resources, 14(4), 579-594.

Keeley, M. (1977). The Economics of family formation, Economic Inquiry, 15(2), 238-250.

Kenny, L., Lee, L., Maddala, G.S. \& Trost, R.P. (1979), Returns to college education: An investigation of self-selection bias based on the project TALENT data, International Economic Review, 20, 775-789. 
Kenny, L. (1983). The accumulation of human capital during marriage by males. Economic Inquiry, 21(2), 223-231.

Knowles, J. A. (2013). Why are married men working so much? an aggregate analysis of intrahousehold bargaining and labour supply. The Review of Economic Studies, 80(3), 1055-1085.

Korenman, S. \& Neumark, D. (1991). Does marriage really make men more productive?. The Journal of Human Resources, 26(2), 248-268.

Nakosteen, R. \& Zimmer, M. (1987). Marital status and earnings of young men. Journal of Human Resources, 22(2), 248-268.

Nakosteen, R. \& Zimmer, M. (2001). Spouse selection and earnings: Evidence of marital sorting. Economic Inquiry, 39(2), 201-213.

Parsons, D. (1977). Health, family structure, and labor supply. American Economic Review, 67, 703-712.

Pollmann-Schult, M. (2011). Marriage and Earnings: An Investigation into the Causes of the Male Marriage Wage Premium. European Sociological Review, 27(2), 147-63.

Yang, C. \& Lin, H. (2012) "Is there salary discrimination by nationality in the NBA?: Foreign talent or foreign market. Journal of Sports Economics, 13(1), 53-75. 


\section{Appendix 1}

Comparison between standard and logarithmic distributions of EFF

\section{Standard and Normal Distributions (EFF)}

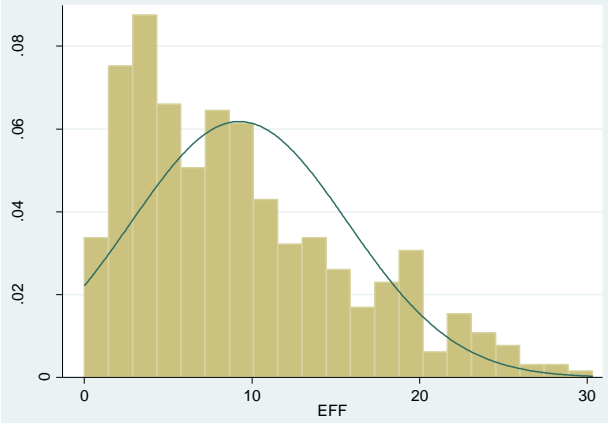

Log (EFF) and Normal Distribution

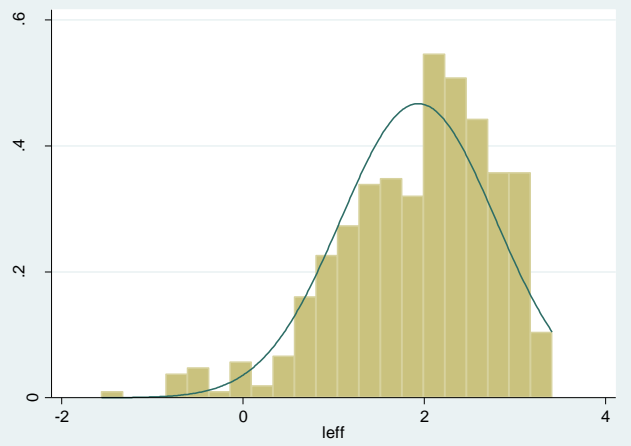

